\title{
CHARACTERISATION OF ASYMMETRIC ALUMINA HOLLOW FIBRE MEMBRANES
}

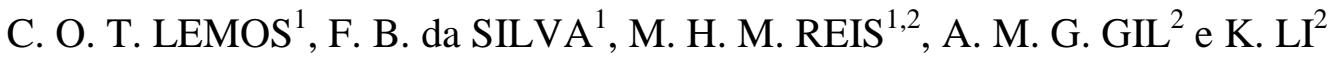 \\ ${ }^{1}$ Universidade Federal de Uberlândia, Faculdade de Engenharia Química \\ ${ }^{2}$ Imperial College London, Chemical Engineering Department \\ E-mail contact: miria@feq.ufu.br
}

\begin{abstract}
Ceramic membranes are widely used for separations. They can be configured as flat discs, finite tubes or hollow fibres. Hollow fibres present some advantages such as the higher ratio between membrane and system areas. Moreover, the asymmetric structure, presenting regions of different pore sizes, should be carefully prepared in order to achieve greater permeabilities. Here we analyze the permeability and the morphology of asymmetric alumina hollow fibres which were prepared at different conditions. The hollow fibres were fabricated using the phase inversion/sintering method. Different internal coagulants and sintering temperatures were applied. The hollow fibres were characterised by scanning electronic microscopy, water and nitrogen permeations and mechanical strength. The obtained results showed that more fingers are obtained when solvent mixed with water is used as internal coagulant, instead of pure water. As consequence, these membranes presented greater permeabilities. The permeability also increased with the decrease in the sintering temperature. However, the decrease in the sintering temperature decreased the mechanical strength of the fibre. In conclusion, more permeable asymmetric hollow fibres were obtained using solvent as internal coagulant and applying lower sintering temperatures.
\end{abstract}

\section{INTRODUCTION}

The separation membrane processes have been used in different segments such as chemical industry, medical area, biotechnology, food and pharmaceutical industry, and for water treatment (Habert et al., 2006). Regarding to the material applied for membrane synthesis, the most common ones are polymeric and ceramic. Ceramic membranes can be used in many applications including filtration for corrosive fluids and solid oxide fuel cells due to their ability to operate at high temperatures and pressures, and in corrosive environments (Kingsbury and Li, 2009). The most widely used membrane geometries are tubular or flat. However, the use of ceramic hollow fibres, instead of finite tubes, allows a higher ratio between the surface area and volume of the membrane system. Pan et al. (2003) managed to fabricate and employ $\mathrm{Al}_{2} \mathrm{O}_{3}$ hollow fibre with much higher packing density (as high as $1000 \mathrm{~m}^{2} / \mathrm{m}^{3}$ ).

The immersion induced phase inversion method, first described by Loeb and Sourirajan (1963) for polymeric membranes, allows the achievement of an asymmetric structure for the membrane in a single step (Wu et al., 2013; Kingsbury and Li, 2009). Asymmetric membranes 
presents at least two main regions of different pore sizes: a sponge like layer with smaller pore sizes and a region with micro channels of larger pore sizes. The major characteristic of this method is the flexibility in forming radial micro channels, which consequently leads to a number of new asymmetric membrane structures that can hardly be achieved in a single-step via conventional fabrication techniques. Because of these micro-channels the mass transfer resistance is quite reduced when compared to conventional symmetric structure. The sponge like layer ensures the necessary mechanical strength for the membrane. Thus, the asymmetric pore structure with an outer sponge layer and an inner layer with larger filaments has favourable characteristics for a higher permeation (Garcia-Garcia et al., 2011).

The literature presents some paper related to the fabrication of ceramic asymmetric hollow fibres (Sun et al., 2006; Kingsbury and Li, 2009; Li et al., 2006). These papers presents the morphology of the membranes by regulating parameters like suspension composition, air gap, extrusion rate, bore liquid and flow rate. Moreover, the applied sintering temperature is related to the densification of the sponge-like layer and, thus, with its mechanical strength (Sun et al., 2006; Kingsbury and $\mathrm{Li}, 2009$ ). However, it is necessary to investigate more specific structures that enable higher permeating fluxes.

The main objective of this research is to evaluate the characteristics of hollow fibres prepared using different sintering temperatures and internal coagulant compositions. These hollow fibres were characterised according to their morphology, mechanical strength, and water and nitrogen permeabilities.

\section{MATERIAL AND METHODS}

\subsection{Materials}

The ceramic hollow fibre substrates were fabricated using aluminium oxide powder of $1.0 \mu \mathrm{m}$ (alpha, 99.9\% metal basis, surface area 6-8 $\mathrm{m}^{2} \mathrm{~g}^{-1}$ ), purchased from Alfa Aesar. The ceramic suspension was prepared using Polyethersulfone (PESf, Radel A-300, Ameco Performance, USA), DMSO (VWR) and Arlacel P135 (Uniqema, UK) as polymer binder, solvent and additive, respectively.

\subsection{Fabrication of asymmetric $\mathrm{Al}_{2} \mathrm{O}_{3}$ hollow fibre membranes}

The asymmetric $\mathrm{Al}_{2} \mathrm{O}_{3}$ hollow fibres were fabricated using the phase inversion/sintering method (Kingsbury and Li, 2009). Arlacel P135 was dissolved in DMSO prior to the addition of aluminium oxide powders. The mixture was rolled/milled for $48 \mathrm{~h}$. After this, the polymer was added and the suspension was rolled/milled for further $48 \mathrm{~h}$. The suspension was then transferred to a gas tight reservoir and degassed under vacuum. After degassing, the spinning suspension was extruded through a tube-in-orifice spinneret (outer diameter $3 \mathrm{~mm}$, inner diameter $1.2 \mathrm{~mm}$ ) into the external coagulation bath with different air gaps (distance between the fibre precursor and the external coagulant bath). The scheme of the hollow fibres preparation is presented in Figure 1. Tap water was used as external coagulant. The produced fibre precursors were kept in water for $12 \mathrm{~h}$ in order to remove the excess of solvent and to allow complete phase inversion.

After drying for $48 \mathrm{~h}$ under atmospheric conditions during, fibre precursors were sintered in a tubular furnace (Elite, Model TSH 17/75/450). The temperature was increased from room 
temperature to $600^{\circ} \mathrm{C}$ at a rate of $2^{\circ} \mathrm{C} \min ^{-1}$ followed by a dwell of $2 \mathrm{~h}$. In a second stage, the temperature was increased to 1300 or $1400^{\circ} \mathrm{C}$ (target temperature) at a rate of $5^{\circ} \mathrm{C} \mathrm{min}^{-1}$ followed by a dwell of $4 \mathrm{~h}$. After the sintering was completed, the hollow fibres were cooled to room temperature at a rate of $3^{\circ} \mathrm{C} \mathrm{min}^{-1}$.

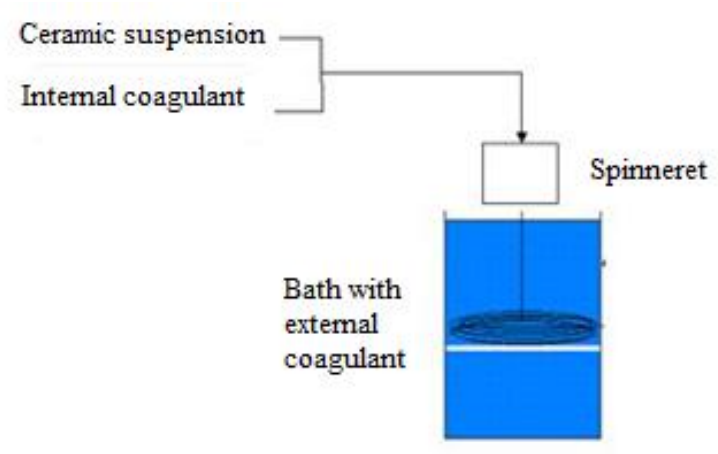

Figure 1. The extrusion process scheme.

The different manufacturing parameters of each fibre are described in Table 1. The fibre HF1-1400 was prepared using water as the internal coagulant. Water is responsible for the coagulation of the ceramic suspension and, consequently, the formation of micro-voids across the fibre. Using water as internal and external coagulants (Fibre HF1-1400) an air gap is necessary in order to allow the formation of the sponge like layer in the outer surface of the fibre; otherwise the micro-voids would be formed in inner and outer surfaces of the fibre. The fibre HF1-1400 was sintered at $1400^{\circ} \mathrm{C}$. No air gap was used during the fabrication of the fibres HF2-1300, HF3-1300 e HF3-1400 since solvent or a mixture of solvent and water was used as the internal coagulant and, thus, the formation of the micro-voids in these fibres was from the outer to the inner surface of the fibre because water was used as the external coagulant. The fibre HF2-1300 was sintered at $1300^{\circ} \mathrm{C}$. For the fibres HF3-1300 and HF3-1400 the applied sintering temperatures were of 1300 and $1400^{\circ} \mathrm{C}$, respectively.

Table 1 - Fabrication parameters of the fibres.

\begin{tabular}{llll}
\hline Sample & Internal Coagulant & Air Gap $(\mathrm{cm})$ & Sintering Temperature $\left({ }^{\circ} \mathrm{C}\right)$ \\
\hline HF1-1400 & Water & 3 & 1400 \\
HF2-1300 & Solvent & 0 & 1300 \\
HF3-1300 & Solvent+Water & 0 & 1300 \\
HF3-1400 & Solvent+Water & 0 & 1400 \\
\hline
\end{tabular}

\subsection{Characterisation of asymmetric $\mathrm{Al}_{2} \mathrm{O}_{3}$ hollow fibre substrates}

Scanning electron microscopy (SEM): The asymmetric $\mathrm{Al}_{2} \mathrm{O}_{3}$ hollow fibres were characterised according to their morphology and structure using a scanning electron microscope (EVO MA 10, Carl Zeiss) and a secondary electron detector.

Mechanical strength: The bending strength $\left(\sigma_{\mathrm{F}}\right)$ of the hollow fibre was determined by the bending test using an Instron Model 4466 provided with a load cell for $1 \mathrm{kN}$ and was calculated using the Equation (1) (Othman et al., 2011). 
$\sigma_{F}=\frac{8 F L D_{o}}{\left(D_{o}^{4}-D_{i}^{4}\right)}$

where $F$ is the measured load in which the fracture occurred $(N), L$ is the length $(m)$ of the sample, and $\mathrm{D}_{\mathrm{o}}$ and $\mathrm{D}_{\mathrm{i}}$ are the outer and the inner diameter of the sample, respectively.

Permeability: Nitrogen $\left(\mathrm{N}_{2}\right)$ and water $\left(\mathrm{H}_{2} \mathrm{O}\right)$ flux measurements were carried out at different transmembrane pressures and at room temperature in order to investigate the permeability of the prepared hollow fibres. For these flux measurements, the hollow fibre with one-end sealed was glued with epoxy-resin (Araldite®) on a stainless steel holder that was connected to the permeation apparatus (Figure 2). For the nitrogen flux tests, the gas feed pressure was adjusted using a pressure regulator (OMEGA, PRG101-120) and monitored using a pressure gauge with a resolution of 0.1 psi (OMEGA, DPG1000B-10G), as shown in Figure 2a. The gas was fed to the shell side of the fibre and collected from the lumen side. The $\mathrm{N}_{2}$ flux was measured at several transmembrane pressures (from 20 to $250 \mathrm{kPa}$ ) using a bubble flow meter. The water flux was measured in a cross-flow configuration, as shown in Figure $2 \mathrm{~b}$. The mass of the permeated water was measured at several transmembrane pressures (from 20 to $150 \mathrm{kPa}$ ) and the flux was calculated applying the Equation (2).

$J=\frac{m}{A t}$

where $\mathrm{J}$ is the flux $\left(\mathrm{kg} \mathrm{m}^{-2} \mathrm{~s}^{-1}\right)$, $\mathrm{m}$ is the permeate mass $(\mathrm{kg}), \mathrm{A}$ is the effective surface area of the fibres $\left(\mathrm{m}^{2}\right)$ and $\mathrm{t}$ is the time of the permeate collection (s).

The effective surface area (A) was calculated according to Equation (3), as suggested by Tan et al. (2005):

$A=\frac{2 \pi L\left(r_{o}-r_{i}\right)}{\ln \left(r_{o} / r_{i}\right)}$

where $\mathrm{L}$ is the fibre length and $r_{o}$ and $r_{i}$ are the outer and inner radius of the fibre, respectively.

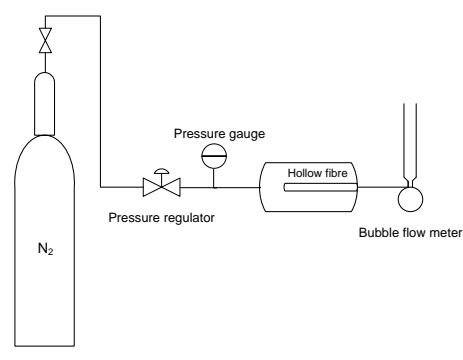

(a)

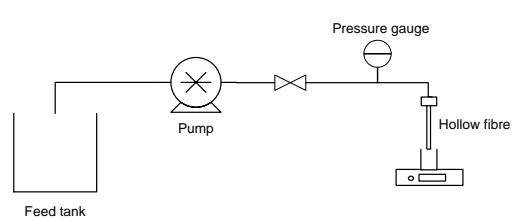

(b)

Figure 2 - Schematic diagram of nitrogen (a) and water (b) permeation apparatus.

\section{RESULTS AND DISCUSSION}

Figures 3, 4, 5 and 6 show the images of the fibre structure obtained by SEM. The obtained hollow fibres presented the desired morphological asymmetric structure, with an 
outer sponge like layer and inner micro-channels covering a large extension of the fibre. The inner micro-channels will ensure greater permeabilities through the fibre. The outer sponge like layer is denser than the inner micro-channels and will provide the required mechanical strength for the hollow fibre.

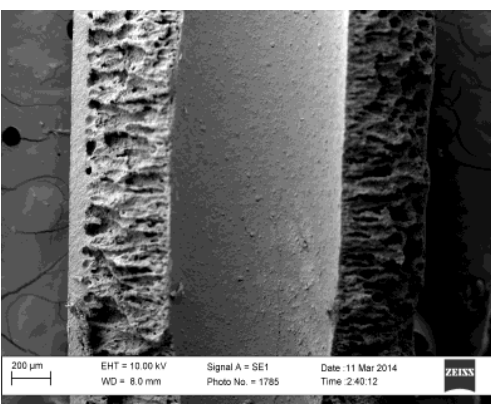

(a)

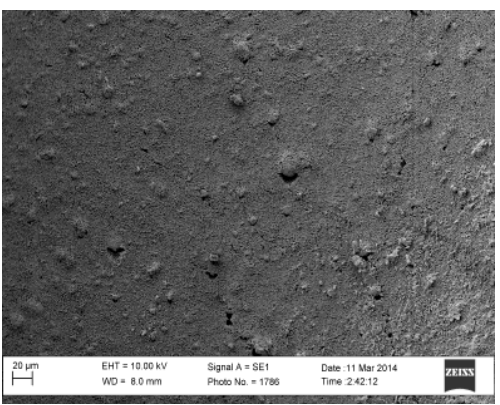

(b)

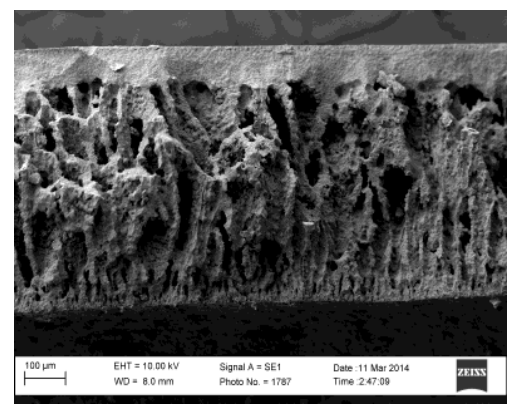

(c)

Figure 3. SEM images of the membrane HF1-1400: (a) Overview cross section, (b) inner surfaces and (c) fibre wall.

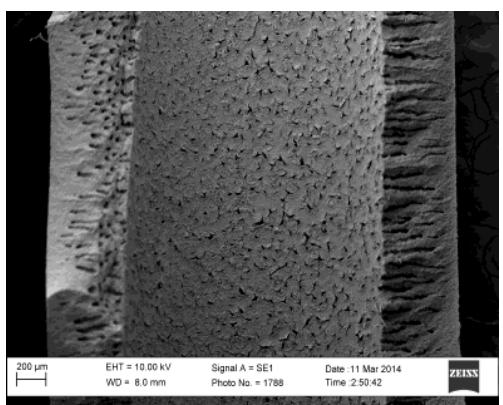

(a)

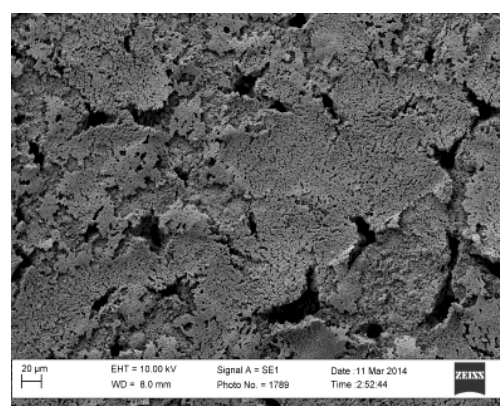

(b)

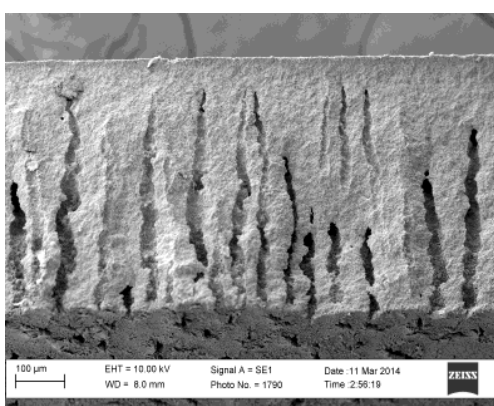

(c)

Figure 4. SEM images of the membrane HF2-1300: (a) Overview cross section, (b) inner susfaces and (c) fibre wall.

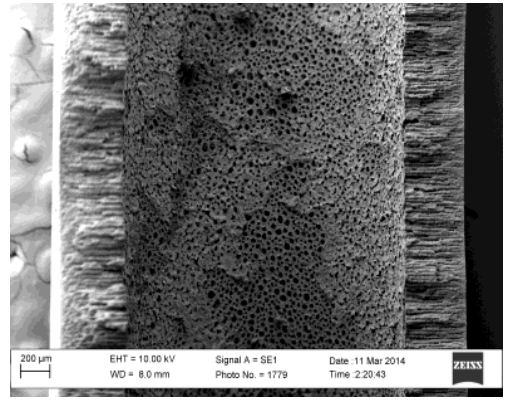

(a)

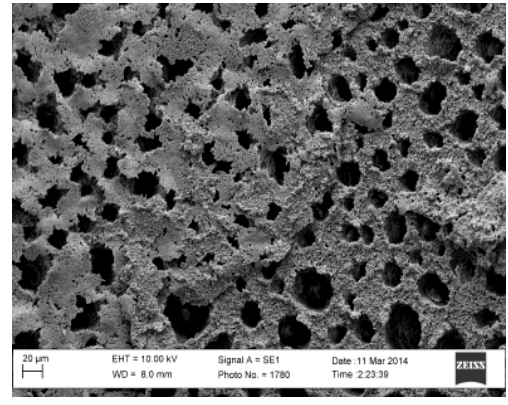

(b)

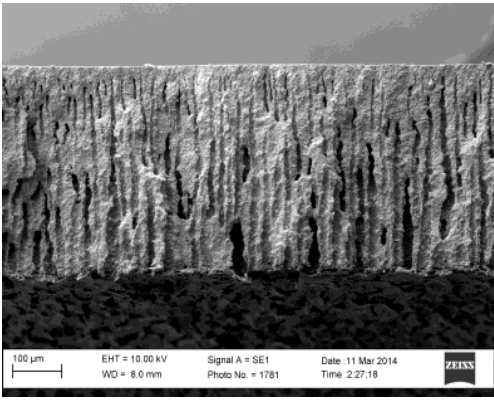

(c)

Figure 5. SEM images of the membrane HF3-1300: (a) Overview cross section, (b) inner susfaces and (c) fibre wall. 

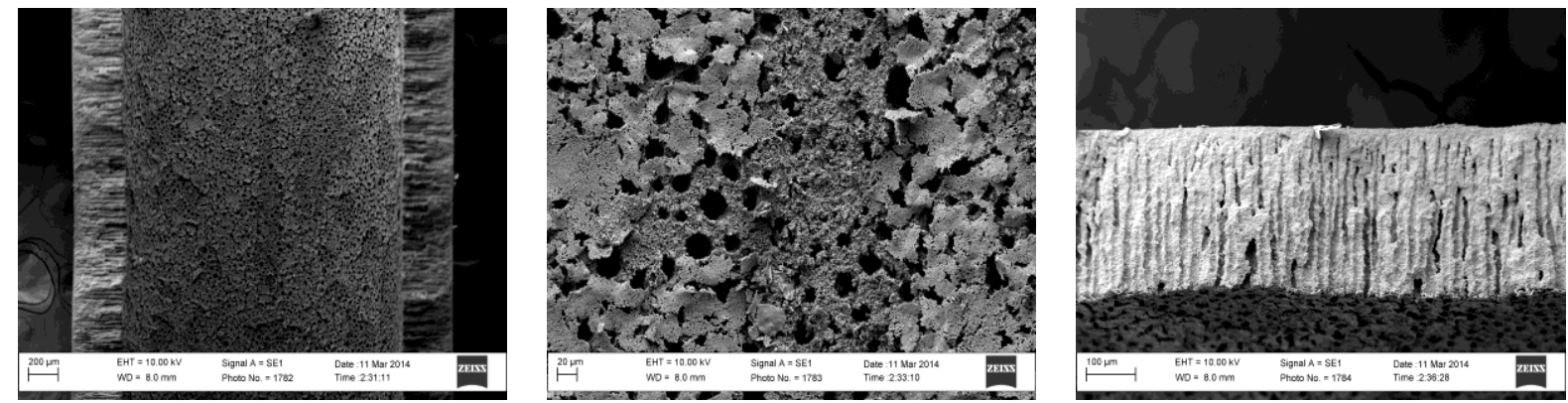

Figure 6. SEM images of the membrane HF3-1400: (a) Overview cross section, (b) inner susfaces and (c) fibre wall.

Depending on the applied sintering temperature and the used internal coagulant, the obtained hollow fibres presented different morphological aspects. Figure 3 a shows that the micro-channels of the hollow fibre HF1-1400 were blocked in the inner layer of the fibre. The application of water as the internal coagulant can be responsible for a ceramic precipitation that blocked the formed micro-channels. This blockage can decrease the fibre permeability besides making difficult the application of this fibre as support for catalyst deposition, for instance. In fact, for this fibre (HF11400) there are two sponge like layers, one inside and another one outside the fibre. Figure 3c shows that the filaments were formed irregularly and not along the fibre.

According to Figures $4 \mathrm{a}$ e $4 \mathrm{~b}$, the fibre HF2-1300 has a structure of micro-channels that were partially blocked. Comparing Figures $3 \mathrm{c}$ and $4 \mathrm{c}$, it is possible to see that the micro-channels formed in the fibre HF2-1300 are thinner and more regular than those formed in the fibre HF11400 due to the action of the solvent as the internal coagulant for the phase inversion process.

Figures 5 and 6 show the structure of the fibres HF3-1300 and HF3-1400, respectively. The application of different sintering temperatures did not affect the morphology of the fibre. However, comparing Figures 5 and 6 with Figures 3 and 4, it is possible to see that the microchannels of the fibres HF3-1300 and HF3-1400 are more numerous and longer than those of the fibres HF1-1400 and HF2-1300. Moreover, comparing Figures 3c, 4c, 5c and 6c, the sponge like layers of the fibres HF3-1300 and HF3-1400 are thinner than the sponge like layers of the fibres HF1-1400 and HF2-1300. However, the micro-channel of the fibres HF3-1300 and HF3-1400 were also partially blocked, as shown in Figures $5 \mathrm{~b}$ and $6 \mathrm{~b}$.

Figure 7 shows the water flux through the proposed hollow fibres. The greater water flow was verified through the fibre HF3-1300, probably because of the greater length and the numerous of micro-channels, in accordance with the SEM pictures shown in Figures 5c and 6c. Comparing the water flow through the fibres HF3-1300 and HF3-1400, it is possible to verify that the increase in the sintering temperature decreased the permeability of the fibre, due to the densification of the sponge like layer. Wu et al. (2013) evaluated the water flow through asymmetric hollow fibre with similar structures of HF1-1400. The values of water flow through the fibres HF1-1400 are consistent with the values given by Wu et al. (2013). 


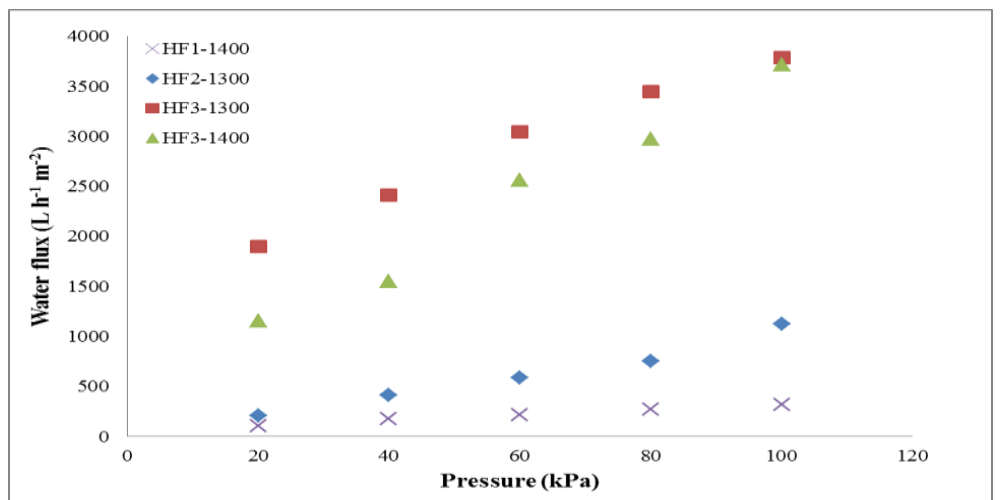

Figure 7 - Water flow through the fibres HF1-1400, HF2-1300, HF3-1300 and HF3-1400.

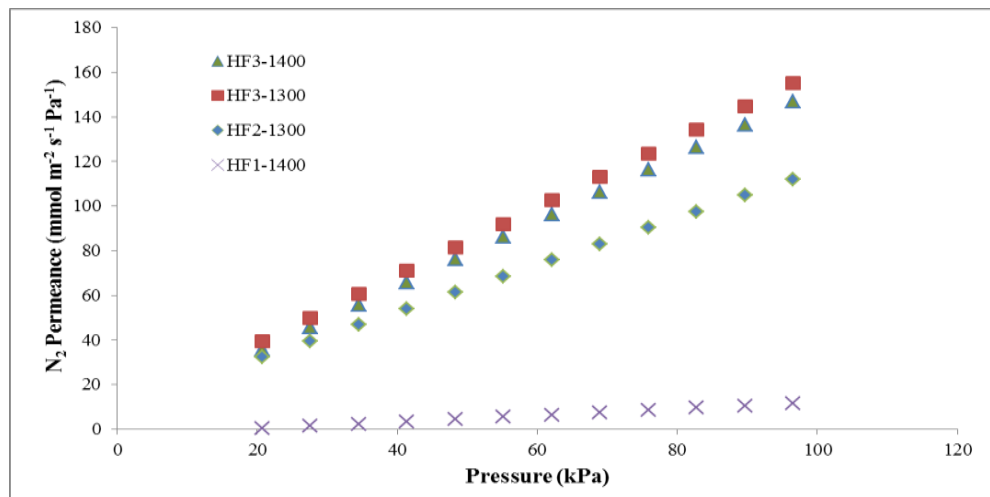

Figure 8- Nitrogen permeance through the hollow fibres HF1-1400, HF2-1300, HF3-1300 and HF3-1400.

Figure 8 shows the $\mathrm{N}_{2}$ permeability through the fibres HF1-1400, HF2-1300, HF3-1300 and HF3-1400. It is observed that the fibre HF3-1300, which has more filaments, has a higher gas permeability than the other ones. The lower permeability of $\mathrm{N}_{2}$ was observed in the fibre HF11400 due to the micro-channels blocked at the inner layer. The reported values of nitrogen permeation through the fibre HF1-1400 are in agreement with Hatim et al. (2011), who used a similar asymmetric hollow fibre.

The mechanical strengths of the fibres HF1-1400, HF2-1300, HF3-1300 and HF3-1400 were 66, 64, 52 and $62 \mathrm{MPa}$, respectively, indicating that these fibres did not have high fragility, although they have a high porosity. The mechanical strength of the fibre is higher when the microchannel region is smaller. Moreover, related to the densification of the sponge like layer, the decrease in the sintering temperature decreased the mechanical strength of the hollow fibre. Sun et al. (2006) produced asymmetric hollow fibres using different internal and external coagulant concentrations and obtained fibres with mechanical strength varying from 36.3 to $122.6 \mathrm{MPa}$. However, the highest mechanical strength reported by Sun et al. (2006) (122.6 MPa) is attributed to a fibre without micro-channels. Thus, the morphology of the hollow fibres obtained in this research, with a large extension of micro-channels and a dense outer layer, ensured simultaneously high porosity and mechanical strength.

\section{CONCLUSION}

The proposed membranes presented the required properties: high mechanical strength, 
smooth outer surface, presence of micro-channels in a large extension of the fibre, high porosity, and high nitrogen and water permeabilities. The decrease in the sintering temperature, from 1400 to $1300^{\circ} \mathrm{C}$, increased the permeabilities through the fibre. However, the decrease in the sintering temperature decreased the mechanical strength of the hollow fibre. Moreover, the choice of the appropriated internal coagulant, which will be responsible for the formation of the micro-channels, is important to have a more permeable hollow fibre. In this research, the hollow fibre formed using a mixture of water and solvent as internal coagulant presented higher permeabilities.

\section{ACKNOWLEDGMENTS}

The authors acknowledge financial support from CNPq and FAPEMIG.

\section{REFERENCES}

GARCIA-GARCIA, F.R., RAHMAN, M.A., KINGSBURY, B. F. K., LI, K. Asymmetric ceramic hollow fibres: New micro-supports for gas-phase catalytic reactions. Applied Catalysis A: General, 393, p. 71-77, 2011.

HABERT, A. C., BORGES, C. P., NOBREGA, R. Processos de separação por membranas. Rio de Janeiro: E-papers, 2006.

HATIM, M. D. I., TAN, X. Y., WU, Z. T., LI, K. Pd/ $\mathrm{Al}_{2} \mathrm{O}_{3}$ composite hollow fibre membranes: Effect of substrate resistances on $\mathrm{H}_{2}$ permeation properties. Chemical Engineering Science, 66, p. 1150-1158, 2011.

KINGSBURY, B.F.K., LI, K. A morphological study of ceramic hollow fibre membranes. Journal of Membrane Science, 328(1-2), p. 134-140, 2009.

LI, K., TAN, X., LIU, Y. Single-step fabrication of ceramic hollow fibres for oxygen permeation. Journal of Membrane Science, 272, p. 1-5, 2006.

LOEB, S., SOURIRAJAN, S. Seawater demineralization by means of an osmotic membrane, Advances in Chemistry Series, 38, p. 117-132, 1963.

OTHMAN, M. H. D., WU, Z. T., DROUSHIOTIS, N., DORASWAMI, U., KELSALL, G., LI, K. Single-step fabrication and characterisations of electrolyte/anode dual-layer hollow fibres for micro-tubular solid oxide fuel cells, Journal of Membrane Science, 351, p. 196-204, 2010.

PAN, X. L., STROH, N., BRUNNER, H., XIONG, G. X., SHENG, S. S. Pd/ceramic hollow fibers for $\mathrm{H}_{2}$ separation. Separation and. Purification. Technology, 32, p. 265-270, 2003.

SUN, G. B., HIDAJAT, K., KAWI, S. Ultra thin Pd membrane on $\mathrm{Al}_{2} \mathrm{O}_{3}$ hollow fiber by electroless plating: High permeance and selectivity. Journal of Membrane Science, 284, p. 110-119, 2006.

WU, Z.T., FAIZ, R., LI, T., KINGSBURY, B.F.K., LI, K. A controlled sintering process for more permeable ceramic hollow fibre membranes. Journal of Membrane Science, 446, p. 286-293, 2013. 